\title{
DÜBLIN
}

Technological University Dublin

ARROW@TU Dublin

\section{High Performance Circularly Polarized Antenna Based on Fractal EBG Structure}

\author{
Xiulong Bao \\ Technological University Dublin, xiulong.bao@tudublin.ie \\ Max Ammann \\ Technological University Dublin, max.ammann@tudublin.ie \\ Giuseppe Ruvio \\ Technological University Dublin
}

See next page for additional authors

Follow this and additional works at: https://arrow.tudublin.ie/engschececon

Part of the Electrical and Computer Engineering Commons

\section{Recommended Citation}

Bao, X. et al. (2006) High performance circularly polarized antenna based on fractal EBG structure. IEEE International Workshop on Antenna Technology Small Antennas and Novel Metamaterials, pp.257-260. March 6-8, 2006, doi:10.1109/IWAT.2006.1609024

This Conference Paper is brought to you for free and open access by the School of Electrical and Electronic Engineering at ARROW@TU Dublin. It has been accepted for inclusion in Conference papers by an authorized administrator of ARROW@TU Dublin. For more information, please contact arrow.admin@tudublin.ie, aisling.coyne@tudublin.ie,gerard.connolly@tudublin.ie.

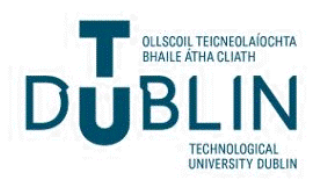




\section{Authors}

Xiulong Bao, Max Ammann, Giuseppe Ruvio, and Matthias John 


\title{
High Performance Circularly Polarized Antenna Based on Fractal EBG Structure
}

\author{
X.L.Bao, M.J.Ammann, G., Ruvio, M., John \\ Centre for Telecommunications Value-chain driven Research, \\ School of Electronic \& Communications Engineering, \\ Dublin Institute of Technology, Kevin Street, Dublin 8, Ireland
}

\section{INTRODUCTION}

Circularly polarized patch antennas have been widely applied in wireless communication system, global positioning system, etc., because of their low-profile, lightweight, ease of fabrication and low lost [1,2]. To achieve high performance for circularly polarized patch antennas, some new structures were reported in the literature, such as antennas array, stack layer antennas, using periodic structures [3-7], etc.

In this paper, a high performance circularly polarized low frequency patch antenna based on the compact fractal high-impedance surface EBG structure has been fabricated and experimented. The measured results show that the proposed circularly polarized patch antenna has good performance in impedance bandwidth, axial ratio (AR) bandwidth, and gain.

\section{THE NOVEL EBG CIRCULARLY POLARIZED ANTENNA DESIGN}

A fractal structure is applied on the hi-impedance surface structure in order to reduce the size of EBG cell. The fractal cell is provided using the Minkowski loop generator. The initial shape is the square patch of side $\mathrm{A}\left(0^{\text {th }}\right.$ iteration). For the $1^{\text {st }}$ and $2^{\text {rd }}$ iteration, each side is replaced with new scaled generator $\left(\mathrm{A} 1=\mathrm{A} / 3 ; \mathrm{B} 1=0.5^{*} \mathrm{~A} 1, \mathrm{~A} 2=\mathrm{A} 1 / 3, \mathrm{~B} 2=0.5^{*} \mathrm{~A} 2\right)$, where A1, A2 and B1, B2 are segment and indentation lengths, respectively (Fig.1). The period of the proposed EBG structure is $32.5 \mathrm{~mm}$, and $A=27 \mathrm{~mm}$. A fractal patch connected to the continuous ground plane through a shorting pin constitutes a unit of the lattice. The radius of the shorting pin is $0.5 \mathrm{~mm}$.

The dispersion characteristics of the fractal Hi-Impedance Surface EBG structure is calculated using the Finite Element Method (FEM). The results illustrated in Fig. 2 show a wide bandgap from $1.27 \mathrm{GHz}$ to $2.05 \mathrm{GHz}$.

A square patch antenna with truncated opposite corners is designed as Fig.3, which excites both the $\mathrm{TM}_{01}$ and $\mathrm{TM}_{10}$ orthogonal modes, can produce circularly polarized fields. The square patch antenna size is $56.0 \times 56.0 \mathrm{~m}^{2}$, which have two opposite truncated corners with a side length of $2.8 \mathrm{~mm}$. The feed point is offset from the centre point of the square patch by $9.35 \mathrm{~mm}$. The substrate used is FR4, which has a dielectric constant $\mathcal{E}_{r}=4.4$, the thickness $h=3.04 \mathrm{~mm}$ and the ground plane size is $130 \mathrm{~mm} \times 130 \mathrm{~mm}$. In general, because of the surface wave, the gain of the conventional patch antenna on a high permittivity substrate is low and the bandwidth is very narrow. In this paper, a novel circularly polarized antenna with a fractal EBG structure is presented. This fractal high impedance surface EBG structure is proposed because of its compact size and wide bandwidth features. The performance of this patch antenna is thus improved with the help of EBG structures.

\section{THE MEASUREMENTS}

Fig.4 and Fig. 5 show the return loss and the Smith chart for the proposed circularly polarized antennas, respectively, 
which illustrates an impedance bandwidth from 1660 to1712MHz below $10 \mathrm{~dB}$. The measured axial ratio in the broadside direction against frequency is shown in Fig.6, which axial ratio bandwidth is from 1.678 to $1.705 \mathrm{MHz}$. The measurement results show the centre frequency $1.695 \mathrm{GHz}$ has a minimum axial ratio, about $0.80 \mathrm{~dB}$. The XoZ plane and YoZ plane's radiation patterns at $1.695 \mathrm{GHz}$ are shown in Fig.7. This illustrates a good axial ratio in the upper half-plane. The measured gain for the proposed EBG antenna is $7.0 \mathrm{~dB}$ at $1.695 \mathrm{GHz}$.

\section{CONCLUSIONS}

A circularly polarized patch antenna with a compact fractal electromagnetic bandgap structure substrate is fabricated and experimented. It provides circular polarization with a good axial ratio (AR) within a reasonably wide bandwidth. A significant gain improvement is achieved and the axial ratio is very low in the upper half-plane.

\section{ACKNOWLEDGEMENTS}

This work is supported by the science foundation of Ireland

\section{REFERENCES}

[1]. Kin-Lu Wong, Compact and Broadband Microstrip Antennas, Wiley-InterScience, New York, 2002.

[2]. Wen-shan Chen, Chien-Chin Huang, and Kin-Lu Wong, "Microstrip-Line-Fed Printed Shorted Ring-Slot Antennas for Circular polarization," Microwave and Optical Technology Letters, vol.31, No.2, pp.137-140,October 2001.

[3]. Jieh-Sen Kuo, Gui-Bin Hsieh, "Gain Enhancement of a Circularly Polarized Equilateral-Triangular Microstrip Antenna with s Slotted Ground Plane," IEEE Transactions on Antennas and Propagation, Vol.51, No.7, pp.1652-1656, July 2003.

[4]. Dusan Nesic, Aleksandar Nesic, and Veselin Brankovic, "Circular Polarised Printed Antenna Array with Broadband Axial Ratio," IEEE Antennas and Propagation Society International Symposium, vol.2, pp.912-915, 2003.

[5]. Wai-Kwok Lo, Chi-Hou Chan, and Kwai-Man Luk, "Bandwidth Enhancement of Circularly Polarized Microstrip Patch Antenna using Multiple L-Shaped Probe Feeds," Microwave and Optical Technology Letters, vol.42, No.4, pp.263-265, August 2004.

[6]. Xing Lan, "A Novel High Performance GPS Microstrip Antenna," IEEE Antennas and Propagtion Society International Symposium,vol.2, pp.988-990, 2000.

[7]. M.Rahman and M.A.Stuchly, "Circularly polarized patch antenna with periodic structure," IEE Proc.- Microw. Antenna Propag. vol 149. (3), pp.141-146, June 2002.

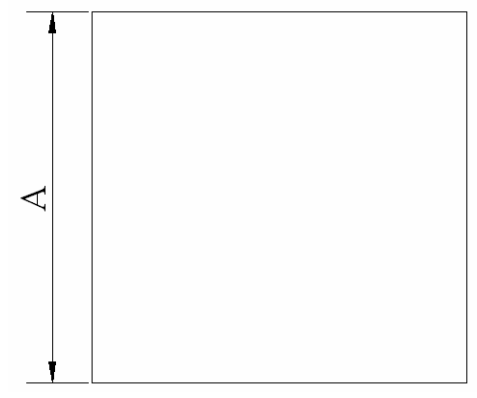

(1) $0^{\text {th }}$ iteration

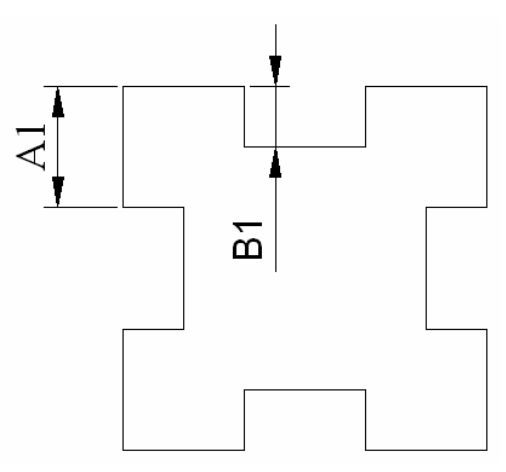

(2) $1^{\text {st }}$ iteration

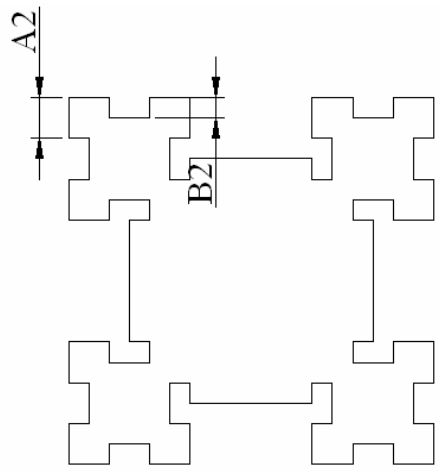

(3) $2^{\text {rd }}$ iteration

Fig.1 The scheme of the fractal hi-impedance structure 


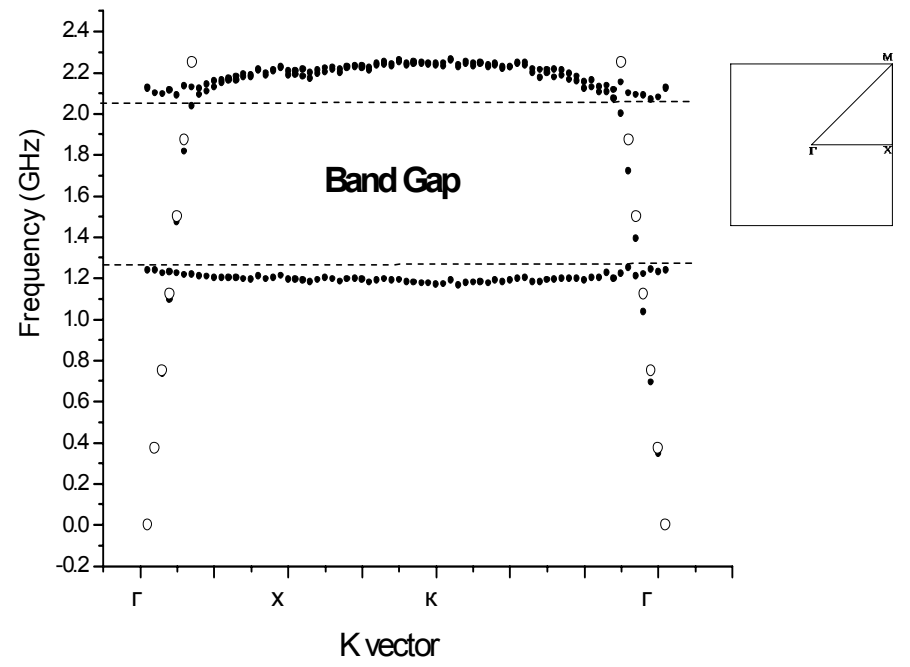

Fig.2 Simulation results for the dispersion curve of two-layer fractal EBG structure
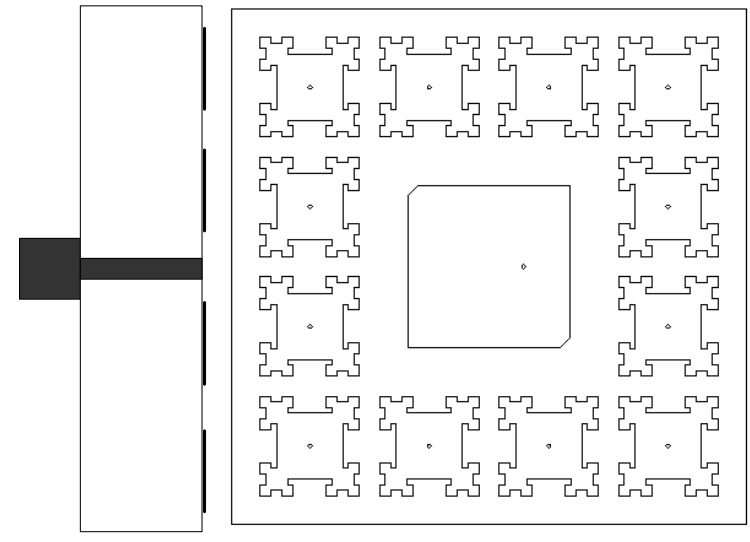

(a) profile

(b) top layer

Fig.3 The Geometries of Circularly Polarized Antennas with Fractal EBG structure

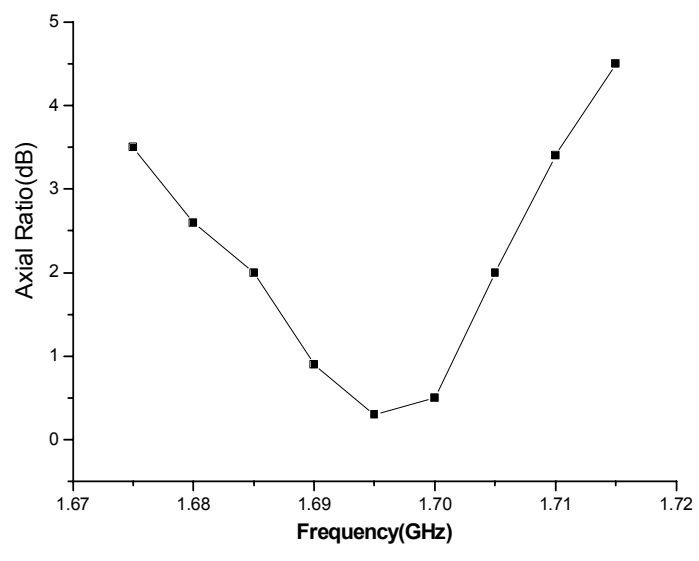

Fig.6 The measurement of the axial ratio for the proposed circularly antennas 


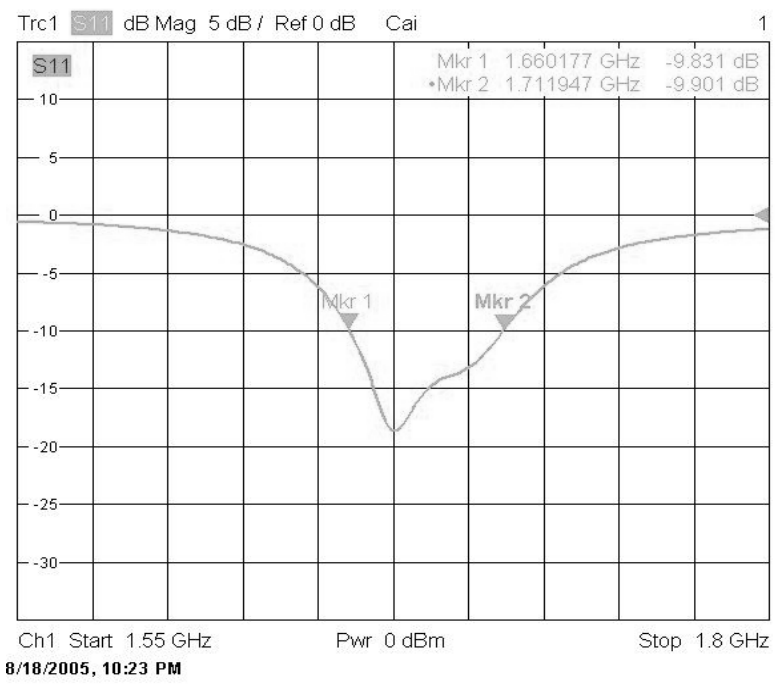

Fig.4 The return loss for the circularly polarized antennas

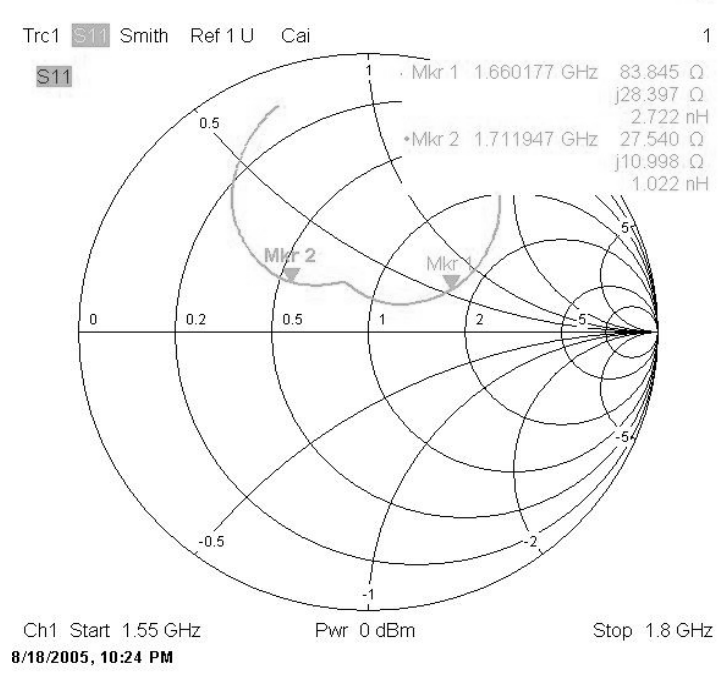

Fig.5 The smith chart for the circularly polarized antennas

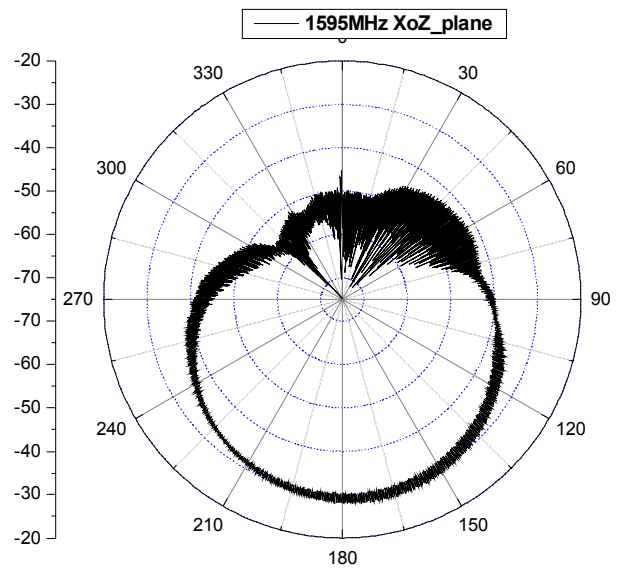

(a) XoZ plane

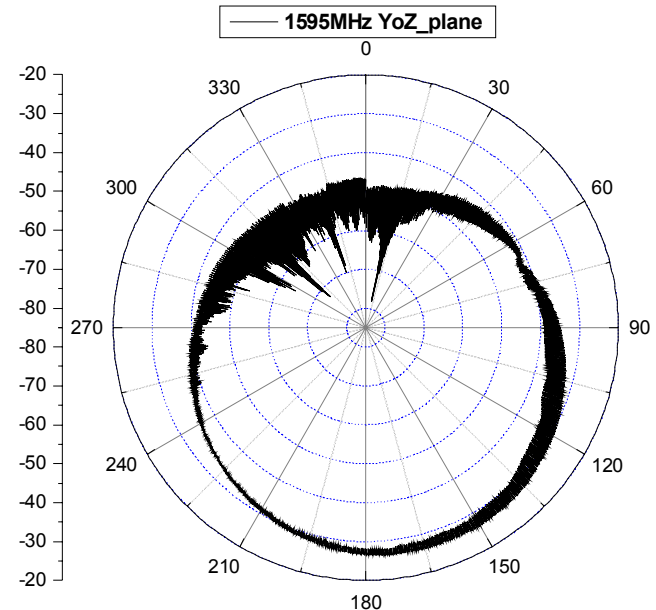

(b) YoZ plane

Fig.7 The spinning radiation patterns for the proposed antennas 